\title{
$\alpha$-tomatine inhibits growth and induces apoptosis in HL-60 human myeloid leukemia cells
}

\author{
HUARONG HUANG ${ }^{1,2}$, SHAOHUA CHEN ${ }^{3}$, JEREMIAH VAN DOREN ${ }^{2}$, DONGLI LI ${ }^{1}, \mathrm{CHELSEA} \mathrm{FARICHON}^{2}$, \\ YAN HE $^{1}$, QIUYAN ZHANG ${ }^{1}$, KUN ZHANG ${ }^{1}$, ALLAN H. CONNEY ${ }^{1,2}$, \\ SUSAN GOODIN $^{4}$, ZHIYUN DU ${ }^{1}$ and XI ZHENG ${ }^{1,2}$ \\ ${ }^{1}$ Allan H. Conney Laboratory for Anticancer Research, Guangdong University of Technology, Guangzhou, \\ Guangdong 510006, P.R. China; ${ }^{2}$ Susan Lehman Cullman Laboratory for Cancer Research, Department of Chemical Biology, \\ Ernest Mario School of Pharmacy, Rutgers, The State University of New Jersey, Piscataway, NJ 08854, USA; \\ ${ }^{3}$ Department of Otolaryngology, Guangdong Provincial People's Hospital, Guangzhou, Guangdong 510006, P.R. China; \\ ${ }^{4}$ Division of Medical Oncology, Rutgers Cancer Institute of New Jersey, New Brunswick, NJ 08903, USA
}

Received June 8, 2014; Accepted November 7, 2014

DOI: $10.3892 / \mathrm{mmr} .2015 .3238$

\begin{abstract}
. $\alpha$-tomatine is a glycoalkaloid that occurs naturally in tomatoes (Lycopersicon esculentum). In the present study, the effects of $\alpha$-tomatine on human myeloid leukemia HL-60 cells were investigated. Treatment of HL-60 cells with $\alpha$-tomatine resulted in growth inhibition and apoptosis in a concentration-dependent manner. Tomatidine, the aglycone of tomatine had little effect on the growth and apoptosis of HL-60 cells. Growth inhibition and apoptosis induced by $\alpha$-tomatine in HL-60 cells was partially abrogated by addition of cholesterol indicating that interactions between $\alpha$-tomatine and cell membrane-associated cholesterol may be important in mediating the effect of $\alpha$-tomatine. Activation of nuclear factor- $\kappa \mathrm{B}$ by the phorbol ester, 12-O-tetradecanoylphorbol-13-acetate failed to prevent apoptosis in HL-60 cells treated with $\alpha$-tomatine. In animal experiments, it was found that treatment of mice with $\alpha$-tomatine inhibited the growth of HL-60 xenografts in vivo. Results from the present study indicated that $\alpha$-tomatine may have useful anti-leukemia activities.
\end{abstract}

\section{Introduction}

The solanum-steroid-alkaloids found in plants of the Solanum species are of interest as a starting material for the synthesis of steroid hormones and exhibit notable pharmaceutical and toxicological properties $(1,2)$. $\alpha$-tomatine and tomatidine

Correspondence to: Dr Xi Zheng, Susan Lehman Cullman Laboratory for Cancer Research, Department of Chemical Biology, Ernest Mario School of Pharmacy, Rutgers, The State University of New Jersey, 164 Frelinghuysen Road, Piscataway, NJ 08854, USA

E-mail: xizheng@pharmacy.rutgers.edu

Key words: glycoalkaloid, $\alpha$-tomatine, leukemia, apoptosis, growth inhibition, cholesterol
(Fig. 1), occur naturally in tomatoes (Lycopersicon esculentum), belonging to the group of solanum-steroid-alkaloids. $\alpha$-tomatine is a glycoalkaloid consisting of an aglycone moiety (tomatidine) and a tetrasaccharide moiety ( $\beta$-lycotetraose), which is composed of two molecules of glucose, one galactose and one xylose; the four monosaccharides form a branched structure, which is attached at the C-3 position of the aglycone (Fig. 1). Although it was known that an enzyme, termed tomatinase, catalyzes the hydrolysis of tomatine into tomatidine and $\beta$-lycotetraose $(3,4)$, the biosynthesis and metabolism of tomatine and tomatidine remain to be elucidated. Unripe green tomatoes may contain up to $500 \mathrm{mg} / \mathrm{kg}$ tomatine fresh fruit weight. The compound is partly degraded as the tomato ripens until at maturity, levels in red tomatoes are $\sim 5 \mathrm{mg} / \mathrm{kg}$ fresh fruit weight (5). $\alpha$-tomatine has also been found at high concentrations in leaves, stems and roots, suggesting that it may be important in resistance to potential pathogens $(3,4)$.

$\alpha$-tomatine has been reported to exert toxicity against certain types of microorganisms (6-8). Previous studies have also demonstrated that $\alpha$-tomatine has cytotoxic effects on insect and rat cells (9-11). In previous years, the anticancer effect of $\alpha$-tomatine has been investigated. $\alpha$-tomatine inhibits the growth of human cancer cells, including the HT-29 colon cancer, HepG2 liver cancer, A549 lung cancer, PC-3 prostate cancer and MCF-7 breast cancer cell lines (12-15). $\alpha$-tomatine also inhibits the growth of lymphoma and leukemia cells $(16,17)$. Although $\alpha$-tomatine has been revealed to have anticancer activities in different cancer cells, the mechanisms of action and particularly the primary target(s) remain to be elucidated. In the present study, the effects and mechanisms of $\alpha$-tomatine were examined in HL-60 human myeloid leukemia cells, which are widely used as a model system to investigate the effect of different anticancer agents $(18,19)$. The present study found that $\alpha$-tomatine markedly inhibited growth and induced apoptosis in HL-60 cells. $\alpha$-tomatine also inhibited the in vivo growth of HL-60 cells in a mouse xenograft model. 


\section{Materials and methods}

Cells and reagents. HL-60 cells were obtained from the American Type Culture Collection (Rockville, MD, USA). Tomatidine, $\alpha$-tomatine and cholesterol were purchased from Sigma-Aldrich (St. Louis, MO, USA). RPMI-1640, penicillin-streptomycin, L-glutamine and fetal bovine serum (FBS) were purchased from Gibco-BRL (Grand Island, NY, USA). HL-60 cells were maintained in RPMI-1640 culture medium containing 10\% FBS that was supplemented with penicillin $(100 \mathrm{U} / \mathrm{ml})$, streptomycin $(100 \mu \mathrm{g} / \mathrm{ml})$ and L-glutamine $(300 \mu \mathrm{g} / \mathrm{ml})$ (Gibco-BRL). Cultured cells were grown at $37^{\circ} \mathrm{C}$ in a humidified atmosphere of $5 \% \mathrm{CO}_{2}$ and were passaged twice a week.

Determination of viable cells. Cell viability was determined by the trypan blue exclusion assay, as described previously (20), which was performed by mixing $80 \mu \mathrm{l}$ of cell suspension and $20 \mu \mathrm{l}$ of $0.4 \%$ trypan blue solution for $2 \mathrm{~min}$. Blue cells were counted as dead cells and the cells that did not absorb dye were counted as live cells.

Morphological assessment of apoptotic cells. Apoptosis was determined by morphological assessment in cells stained with propidium iodide (21). Briefly, cytospin slides were prepared following each experiment and cells were fixed with acetone/methanol (1:1) for $10 \mathrm{~min}$ at room temperature, followed by $10 \mathrm{~min}$ with propidium iodide staining $(1 \mu \mathrm{g} / \mathrm{ml}$ in phosphate-buffered saline; Gibco-BRL) and analyzed using a fluorescence microscope (Nikon Eclipse TE200; Nikon, Tokyo, Japan). Apoptotic cells were identified by classical morphological features, including nuclear condensation, cell shrinkage and formation of apoptotic bodies (21).

Nuclear extract preparation and electrophoretic mobility shift assay (EMSA). Mini-extracts prepared from cells $\left(1 \times 10^{7}\right.$ cells $\left./ \mathrm{ml}\right)$ were collected by centrifugation $(13000 \mathrm{x} \mathrm{g}$ for $10 \mathrm{~min}$ ), resuspended in hypotonic buffer and incubated on ice to obtain the nuclear pellet as described in our previous study (22). Oligonucleotides were synthesized by the DNA Synthesis and Sequencing Laboratory at the Cancer Institute of New Jersey (New Brunswick, NJ, USA). Double-stranded oligonucleotides were labeled by incubation with the Klenow enzyme fragment of DNA polymerase in the presence of ${ }^{32} \mathrm{P}-\mathrm{dCTP},{ }^{32} \mathrm{P}-\mathrm{dGTP}$, dATP and dTTP deoxynucleoside triphosphates. Radiolabeled oligonucleotides (at least $1 \times 10^{8} \mathrm{cpm} /$ $\mu \mathrm{g}$ ) were incubated with $8 \mu \mathrm{g}$ of nuclear protein and $3 \mu \mathrm{g}$ of poly (dI-dC) in a total volume of $16 \mu 1$. DNA-protein complexes were analyzed by electrophoresis on $6 \%$ acrylamide gels run in $1 \mathrm{X}$ Tris-borate buffer (Sigma-Aldrich) (22).

HL-60 xengrafts in immunodeficient mice. Female severe combined immunodeficient (SCID) mice (6-7 weeks old) were obtained from Taconic Farms Inc. (Germantown, NY, USA). The animals were housed in sterile filter-capped microisolator cages and provided with sterilized food and water. HL-60 cells $\left(1.0 \times 10^{6}\right.$ cells $/ 0.1 \mathrm{ml} /$ mouse) suspended in $50 \%$ Matrigel (Collaborative Research, Bedford, MA, USA) in RPMI-1640 medium were injected subcutaneously into the right flank of the mice. After 3 weeks, mice with subcutaneous tumors

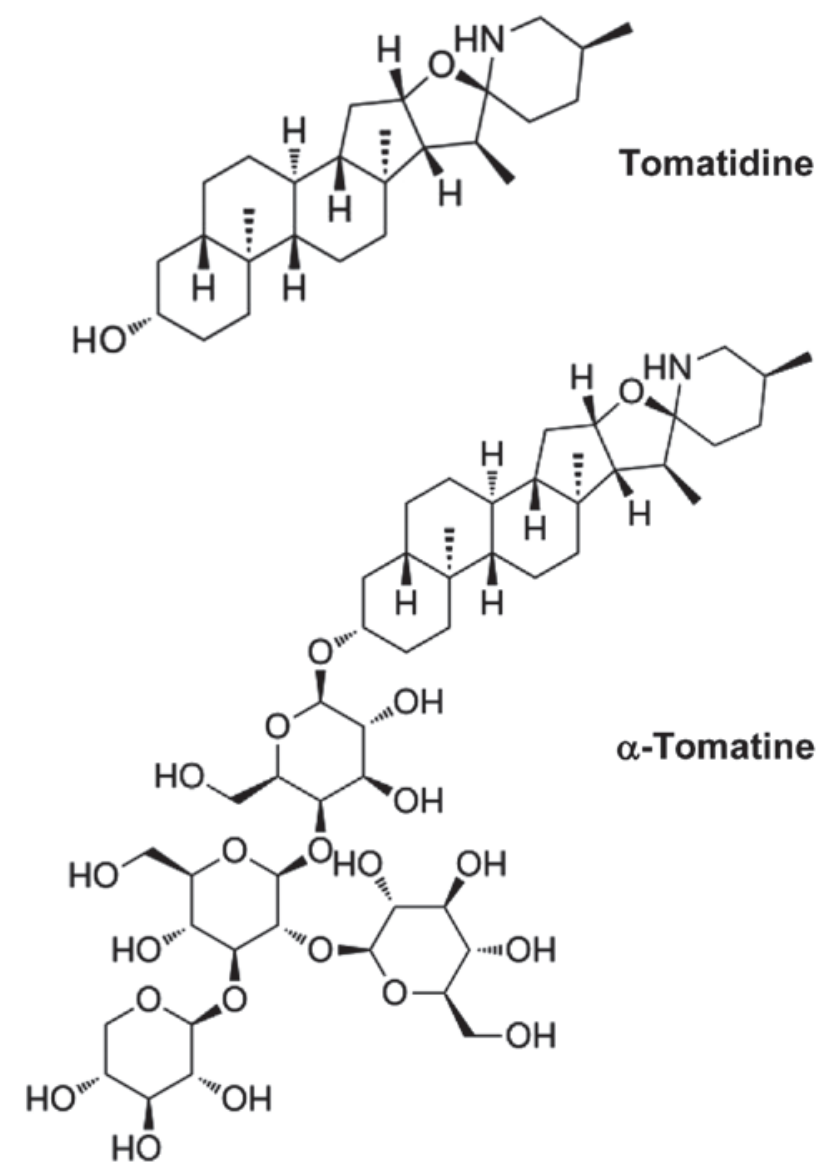

Figure 1. Structures of $\alpha$-tomatine and tomatidine.

were divided into two groups. One group of animals received intraperitoneal (IP) injection of vehicle, which consisted of propylene glycol, polysorbate 80 , benzyl alcohol, ethanol and water (40: 0.5: 1: 10: 48.5). The other group of animals received IP injection of $\alpha$-tomatine $(5 \mathrm{mg} / \mathrm{kg} ; 5 \mu \mathrm{l}$ vehicle $/ \mathrm{g})$. The mice received treatment three times a week for 3 weeks. Tumor size (length $\mathrm{x}$ width) and body weight were measured. The animal experiment was performed under an Institutional Animal Care and Use Committee-approved protocol (\#02-001; Rutgers University, Piscataway, NJ, USA).

Statistical analysis. The analysis of variance method with the Tukey-Kramer test was used for the comparison of growth inhibition and apoptosis. Student's t-test was used to assess the differences of tumor size and body weight between the control group and the treatment group.

\section{Results}

Effects of $\alpha$-tomatine on the growth of HL-60 cells. HL-60 cells were treated with different concentrations of $\alpha$-tomatine for $72 \mathrm{~h}$. The number of viable cells was determined at 24, 48 and $72 \mathrm{~h}$ using the trypan blue exclusion assay (Fig. 2). Treatment of HL-60 cells with $\alpha$-tomatine resulted in a time- and concentration-dependent growth inhibition. $\alpha$-tomatine at 2 and $5 \mu \mathrm{M}$ markedly inhibited the growth of HL-60 cells. Treatment with $\alpha$-tomatine $(5 \mu \mathrm{M})$ resulted in $\sim 98 \%$ decrease in the number of viable cells (Fig. 2A). Cytosine 

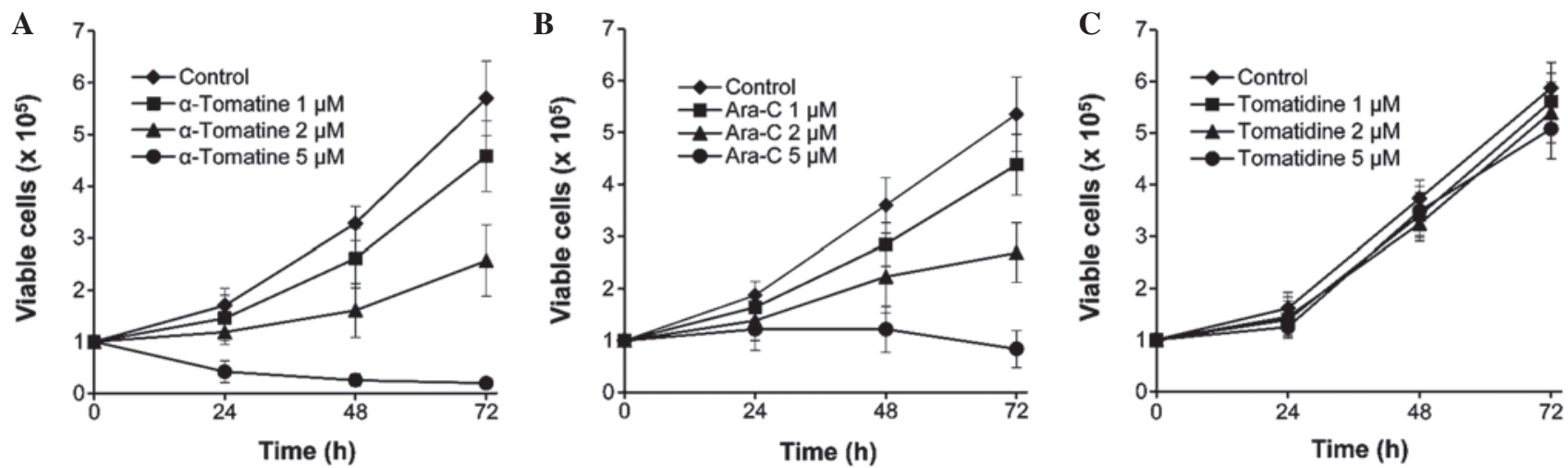

Figure 2. Effects of $\alpha$-tomatine, tomatidine and Ara-C on the growth of HL- 60 cells. HL-60 cells were seeded at a density of $1 \times 10^{5}$ cells $/ \mathrm{ml} \mathrm{in} 35 \mathrm{~mm}$ tissue culture dishes and treated with various concentrations of (A) $\alpha$-tomatine, (B) Ara-C and (C) tomatidine for 24, 48 and $72 \mathrm{~h}$. The number of viable cells was determined using the trypan blue exclusion assay. Each value represents the mean \pm standard error of the mean from three separate experiments. Ara-c, cytosine arabinoside.
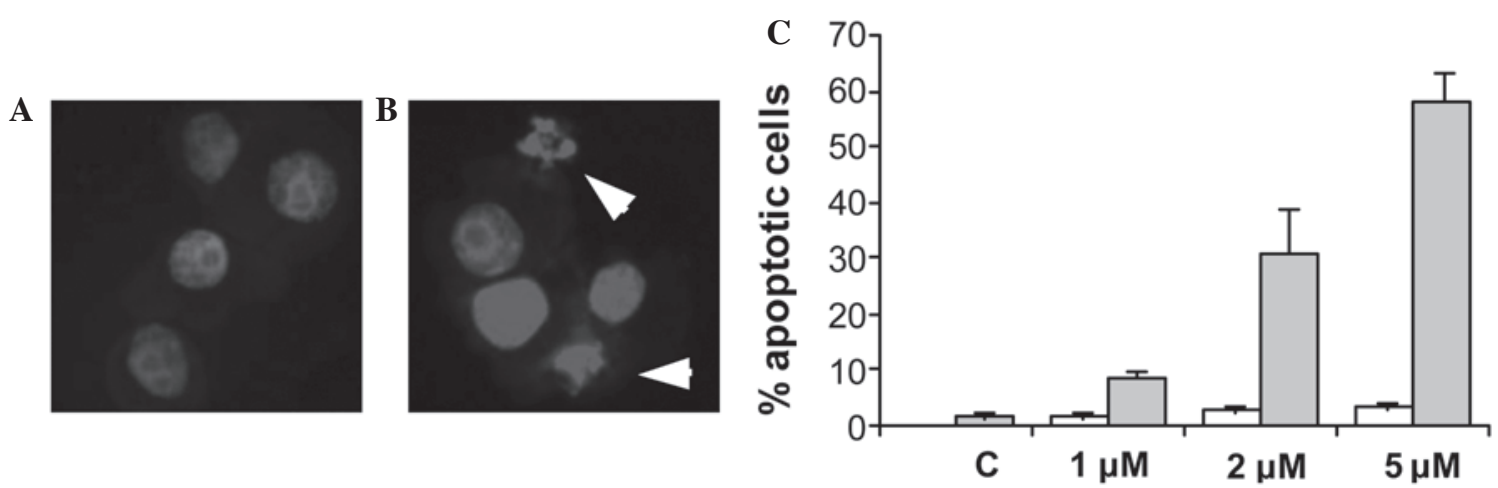

Figure 3. Effect of $\alpha$-tomatine and tomatidine on the apoptosis of HL-60 cells. HL-60 cells were seeded at a density of $1 \times 10^{5}$ cells $/ \mathrm{ml}$ in $35 \mathrm{~mm}$ tissue culture dishes and treated with various concentrations of $\alpha$-tomatine and tomatidine for $48 \mathrm{~h}$. Apoptosis was determined by propidium iodide staining and morphological assessment. Representative micrographs of propidium iodide-stained cells from the (A) control group and cells treated with (B) $2 \mu \mathrm{M} \alpha$-tomatine (arrows indicate apoptotic cells). (C) Percentage of apoptotic cells as determined by morphological assessment in HL-60 cells treated with different concentrations of $\alpha$-tomatine (grey bar) and tomatidine (open bar). Each value represents the mean \pm standard error of the mean from three separate experiments.

arabinoside (Ara-C), a commonly used chemotherapeutic drug for the treatment of myeloid leukemia, was included in the experiment. Treatment of HL-60 cells with Arc-C also resulted in growth inhibition in a time- and concentration-dependent manner (Fig. 2B). $\alpha$-tomatine at $5 \mu \mathrm{M}$ exhibited a more significant growth inhibitory effect than Ara-C. By contrast to the marked growth inhibitory effect of $\alpha$-tomatine, tomatidine (the aglycone of tomatine, see Fig. 1) had little or no effect on the growth of HL-60 cells (Fig. 2C).

Effect of $\alpha$-tomatine on the apoptosis of HL-60 cells. The effects of $\alpha$-tomatine and tomatidine on stimulation of apoptosis in HL-60 cells were determined using morphological assessment of apoptotic cells. Apoptotic cells were identified by classical morphological features, including nuclear condensation, cell shrinkage and formation of apoptotic bodies. Morphologically distinct apoptotic cells from representative samples are shown in Fig. 3B. Treatment of HL-60 cells with $\alpha$-tomatine stimulated apoptosis in a concentration-dependent manner (Fig. 3C). A low concentration of $\alpha$-tomatine $(1 \mu \mathrm{M})$ had little stimulatory effect on HL-60 cell apoptosis. Treatment with $2 \mu \mathrm{M} \alpha$-tomatine resulted in $\sim 30 \%$ apoptotic cells and treatment with a higher concentration of $\alpha$-tomatine $(5 \mu \mathrm{M})$ resulted in $\sim 60 \%$ apoptotic cells. By contrast, tomatidine had little or no stimulatory effect on the apoptosis of HL-60 cells (Fig. 3C).

Effects of cholesterol on $\alpha$-tomatine-induced growth inhibition and apoptosis. It has been established that $\alpha$-tomatine and tomatidine can form complexes with cholesterol $(23,24)$. It was further investigated whether binding of $\alpha$-tomatine with cell membrane cholesterol is required for the effect of this compound on growth inhibition and apoptosis in HL-60 cells. In these experiments, HL-60 cells were treated with $\alpha$-tomatine in the presence or absence of cholesterol and cell growth and apoptosis were determined. The present study found that the addition of cholesterol significantly abrogated $\alpha$-tomatine-induced growth inhibition and apoptosis in HL-60 cells. As shown in Fig. 4A, treatment with $2 \mu \mathrm{M} \alpha$-tomatine decreased the number of viable cells by $\sim 50 \%$. The addition of an equal molar concentration of cholesterol abrogated the effect of $\alpha$-tomatine. The addition of an equal molar concentration of cholesterol also abrogated the effect of tomatine on the stimulation of apoptosis in HL-60 cells (Fig. 4B).

Effects of TPA on $\alpha$-tomatine-induced growth inhibition and apoptosis. The phorbol ester TPA was demonstrated to activate the nuclear transcription factor, nuclear factor $(\mathrm{NF})-\kappa \mathrm{B}$ 


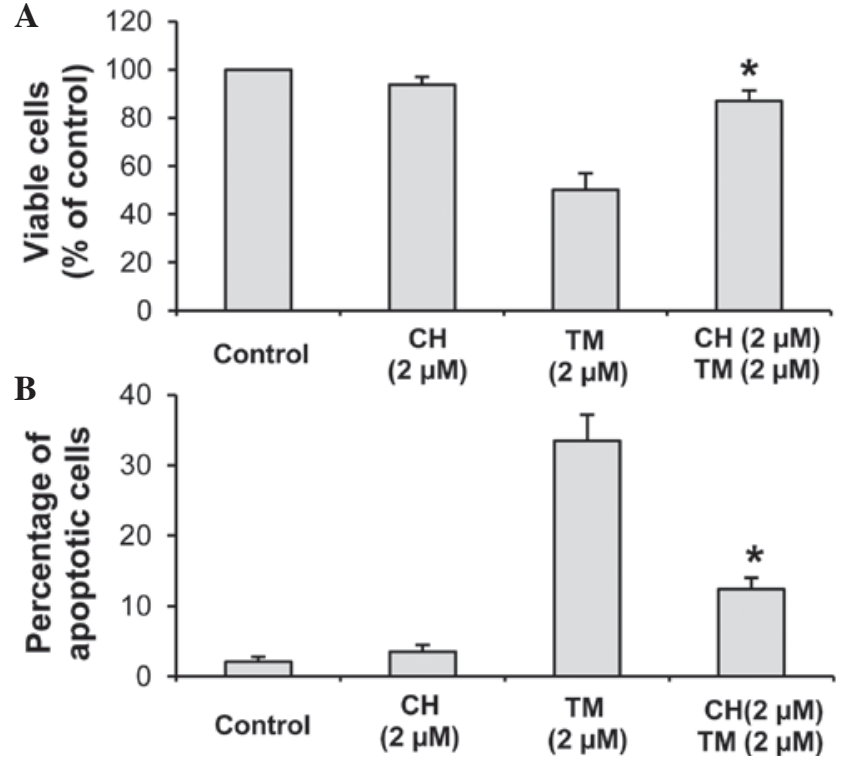

Figure 4. Effects of $\mathrm{CH}$ on TM-induced growth inhibition and apoptosis. HL-60 cells were seeded at a density of $1 \times 10^{5}$ cells $/ \mathrm{ml}$ in $35 \mathrm{~mm}$ tissue culture dishes and treated with TM in the presence or absence of $\mathrm{CH}$ for $48 \mathrm{~h}$. (A) The number of viable cells was determined by the trypan blue exclusion assay. (B) Apoptosis was determined by propidium iodide staining and morphological assessment. Each value represents the mean \pm standard error of the mean from three separate experiments. Differences in the number of viable and apoptotic cells between the TM-treated group and $\mathrm{TM}+\mathrm{CH}$-treated group were analyzed by analysis of variance with the Tukey-Kramer multiple comparison test. "P $<0.01$ vs. TM-treated group. $\mathrm{CH}$, cholesterol; TM, $\alpha$-tomatine.

in cancer cells, including leukemia cells $(22,25,26)$. Multiple studies have indicated that $\mathrm{NF}-\kappa \mathrm{B}$ has an anti-apoptotic effect and activation of $\mathrm{NF}-\kappa \mathrm{B}$ protects cancer cells, including leukemia cells from apoptosis (27-29). It is therefore important to investigate whether pretreatment with TPA may protect HL-60 cells from $\alpha$-tomatine-induced apoptosis. In initial experiments, HL-60 cells were treated with TPA and its effect on activation of $\mathrm{NF}-\kappa \mathrm{B}$ was determined using the EMSA. As shown in Fig. 5A, treatment of HL-60 cells with TPA for $1 \mathrm{~h}$ caused a marked activation of NF- $\kappa$ B. In subsequent experiments, HL-60 cells were pretreated with TPA for $1 \mathrm{~h}$ and then treated with tomatine. However, pretreatment with TPA failed to protect the cells from $\alpha$-tomatine-induced growth inhibition (Fig. 5B) and apoptosis (Fig. 5C).

Effect of $\alpha$-tomatine on the growth of HL-60 xenograft tumors. Female SCID mice with subcutaneous HL-60 xenograft tumors were injected IP with vehicle $(5 \mu \mathrm{l} / \mathrm{g}$ body weight) or $\alpha$-tomatine ( $5 \mathrm{mg} / \mathrm{kg} ; 5 \mu \mathrm{l}$ vehicle $/ \mathrm{g}$ ) three times a week for 3 weeks. As shown in Fig. 6, treatment with $\alpha$-tomatine significantly inhibited the growth of HL-60 tumors. The mean \pm standard error of the mean (SEM) for the percentage of the initial tumor size after 3 weeks of treatment was $475.2 \pm 62.2$ for the control group and 263.9 \pm 25.7 for the $\alpha$-tomatine-treated group. Statistical analysis using Student's t-test revealed that the difference in the percentage of the initial tumor size between the control group and the $\alpha$-tomatine-treated group were statistically significant $(\mathrm{P}<0.01)$. The mean \pm SEM for the body weight $(\mathrm{g})$ was $22.7 \pm 0.9$ for the vehicle-treated control group and $21.8 \pm 1.0$ for the $\alpha$-tomatine-treated group. Statistical analysis using
A

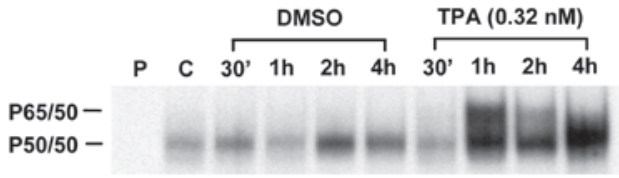

B

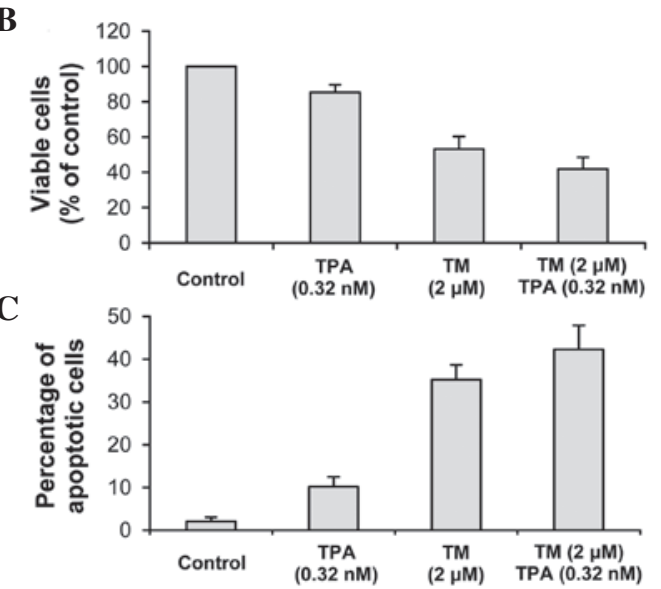

Figure 5. Effects of pre-treatment with TPA on TM-induced apoptosis in HL-60 cells. (A) HL-60 cells were seeded in $100 \mathrm{~mm}$ culture dishes and treated with $0.32 \mathrm{nM}$ TPA for different time intervals. Activation of NF- $\mathrm{\kappa B}$ in HL-60 cells was determined by electrophoretic mobility shift assay. $\mathrm{P}=$ probe only. $\mathrm{C}=$ control. Treatment of HL-60 cells with TPA for $1 \mathrm{~h}$ resulted in a marked activation of NF- $\mathrm{kB}$. (B and C) HL-60 cells were seeded at a density of $1 \times 10^{5}$ cells $/ \mathrm{ml}$ in $35 \mathrm{~mm}$ culture dishes. The cells were treated with TM for $48 \mathrm{~h}$ with or without pre-treatment with $0.32 \mathrm{nM}$ TPA for $1 \mathrm{~h}$. (B) The number of viable cells was determined by the trypan blue exclusion assay and expressed as a percentage of the control. (C) Apoptosis was determined by propidium iodide staining and morphological assessment. TPA, 12-O-tetradecanoylphorbol-13-acetate; TM, $\alpha$-tomatine; $\mathrm{CH}$, cholesterol; DMSO, dimethyl sulfoxide.

A

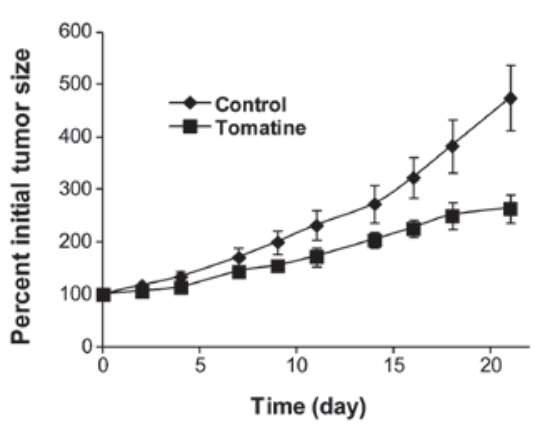

B

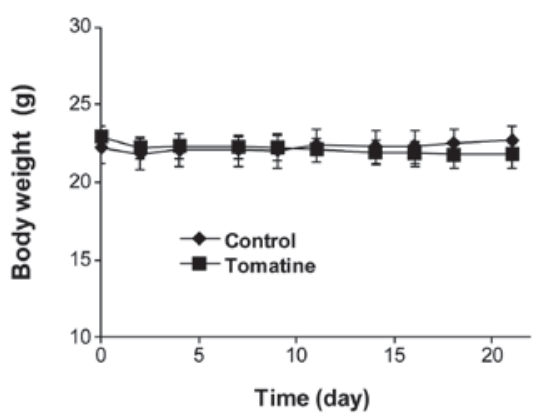

Figure 6. Effects of $\alpha$-tomatine on (A) the growth of HL-60 xenografts and (B) body weight of SCID mice. Female SCID mice were injected subcutaneously with HL-60 cells in 50\% Matrigel $\left(1.0 \times 10^{6}\right.$ cells $\left./ 0.1 \mathrm{ml}\right)$ suspended in RPMI medium. After 3 weeks, mice with HL-60 xenograft tumors (0.6-1.0 cm wide and $0.6-1.0 \mathrm{~cm}$ long) were intraperitoneally injected with vehicle $(5 \mu \mathrm{l} / \mathrm{g}$ body weight; $\mathrm{n}=12)$ or with $\alpha$-tomatine $(5 \mathrm{mg} / \mathrm{kg}$ body weight; $\mathrm{n}=12$ ) three times a week for 3 weeks. (A) Tumor size (length $\mathrm{x}$ width; $\mathrm{cm}^{2}$ ) was measured and expressed as a percentage of initial tumor size. (B) Body weight (g). SCID, severe combined immunodeficient. 
Student's t-test revealed that the difference in the body weight between the control group and the treatment group was not statistically significant $(\mathrm{P}>0.05)$.

\section{Discussion}

Glycoalkaloids are nitrogen-containing secondary plant metabolites found in numerous plants, including potatoes and tomatoes (30). The glycoalkaloid $\alpha$-tomatine has been hypothesized to be involved in host-plant resistance against phytopathogens and has a variety of pharmacological and toxicological properties in animals and humans (5). $\alpha$-tomatine has previously been found to exert anticancer activities $(13-17,31)$. In the present study, the effect of $\alpha$-tomatine and its aglycone, tomatidine was determined in myeloid leukemia HL-60 cells. Although it has previously been reported that $\alpha$-tomatine inhibited growth and induced apoptosis in leukemia cells, the effect of tomatidine on leukemia cells has not been investigated. In the present study it was demonstrated for the first time, to the best of our knowledge, that $\alpha$-tomatine, but not tomatidine inhibited growth and induced apoptosis in HL-60 cells indicating the importance of the glycone compartment of this compound. It was also found that $\alpha$-tomatine was as potent as the widely used anti-leukemia drug Ara- $\mathrm{C}$ for inhibiting the growth and stimulating the apoptosis of HL-60 cells.

The mechanisms by which $\alpha$-tomatine induces growth inhibition and apoptosis in myeloid leukemia cells remain to be elucidated. A previous study revealed that treatment with $\alpha$-tomatine resulted in activation of Bak and Mcl-1s, and caused release of apoptosis inducing factor and suppression of survivin (16). Other studies demonstrated that $\alpha$-tomatine inhibited the NF- $\mathrm{BB}$ and phosphatidyl-inositol-3-kinase/Akt signaling pathways activation in lung and prostate cancer cells $(13,15)$. However, the primary cellular target(s) for $\alpha$-tomatine and its mechanisms for modulating apoptosis-associated pathways remain to be elucidated. Previous in vitro studies revealed that $\alpha$-tomatine forms a robust complex with cholesterol in aqueous media $(23,24)$ and $\alpha$-tomatine was used as a cholesterol probe (32). Keukens et al (33) demonstrated that $\alpha$-tomatine and other glycoalkaloids interacted with membrane-associated cholesterol. In the present study, it was investigated whether the interaction of $\alpha$-tomatine with cell membrane-associated cholesterol is essential for its effects on leukemia cells. It was found that inhibiting the interaction of $\alpha$-tomatine with cell membrane-associated cholesterol by addition of equal molar concentrations of free cholesterol in the medium abrogated the effect of $\alpha$-tomatine. This is the first study, to the best of our knowledge, indicating that the interaction of tomatine with cholesterol is important for mediating its effect on growth and apoptosis in leukemia cells. The interaction of $\alpha$-tomatine with cholesterol and the disruptive effect on the cell membrane may be one of the mechanisms by which $\alpha$-tomatine induces apoptosis in HL-60 cells. It is also possible that the formation of complexes of $\alpha$-tomatine and cholesterol may modulate the responsiveness of cell membrane receptors to growth stimuli and thus decrease the growth of HL-60 cells.

To further investigate whether the glycone group is required for $\alpha$-tomatine to inhibit growth and induce apoptosis, the effects of $\alpha$-tomatine with its aglycone tomatidine on HL-60 cells were investigated. Although previous studies have revealed that tomatidine was able to interact and form a complex with cell membrane-associated cholesterol $(23,24)$, it was found that tomatidine had little effect on growth inhibition and apoptosis at the doses assessed. Other studies have demonstrated that glycoalkaloids caused membrane disruption leading to the release of peroxidase previously enclosed in lipid vesicles $(33,34)$. It was observed that $\alpha$-tomatine increased the fluorescence-measured membrane permeability of frog embryos while tomatidine had a weak effect (5). $\alpha$-tomatine also decreased active transport via the activity of the sodium-potassium pump in frog skin, however, tomatidine had no effect on frog skin (5). These results, together with the present findings suggest that the glycone component is important for mediating the effects of $\alpha$-tomatine on growth inhibition and apoptosis. In additional studies, it was investigated whether pre-treatment with the phorbol ester TPA may protect HL-60 cells from apoptosis induced by $\alpha$-tomatine. Although the present study demonstrated that treatment with TPA resulted in a marked activation of $\mathrm{NF}-\kappa \mathrm{B}$, pre-treatment with TPA did not protect HL-60 cells from $\alpha$-tomatine-induced apoptosis. This result suggests that $\alpha$-tomatine may also trigger pathways that are not associated with $\mathrm{NF}-\kappa \mathrm{B}$ to induce apoptosis in HL-60 cells.

The present study also demonstrated an in vivo effect of $\alpha$-tomatine. Treatment of SCID mice with IP injection of $\alpha$-tomatine three times a week significantly inhibited the growth of HL-60 cells in vivo. At the dose of $5 \mathrm{mg} / \mathrm{kg}$ body weight used in the present study, $\alpha$-tomatine appeared to be non toxic as no body weight loss and no abnormalities in the major organs were observed in the animals. Previous studies revealed that $\alpha$-tomatine was not toxic when consumed orally by rats (35-37). When administered intravenously, it had a median lethal dose value equal to $18 \mathrm{mg} / \mathrm{kg}$ body weight $(35,36)$. Nishie et al (38) revealed that IP injection of $\alpha$-tomatine $(30-100 \mathrm{mg} / \mathrm{kg})$ in rabbits produced neither fatalities nor abnormal ECG signals. Although the plasma concentrations of $\alpha$-tomatine in these studies were not known, it is reasonable to assume that blood concentration of $\alpha$-tomatine at micromolar level may be achievable without severe toxicity. Further studies are required to establish the plasma levels of $\alpha$-tomatine in association with its inhibitory effect on leukemia and other types of cancer in suitable animal models.

In conclusion, the present study demonstrated that $\alpha$-tomatine had a marked inhibitory effect on growth and a marked stimulatory effect on apoptosis in human myeloid leukemia HL-60 cells. $\alpha$-tomatine also significantly inhibited the in vivo growth of HL-60 cells in the SCID mouse xenograft model. The present study suggests that cell membrane-associated cholesterol serves as a primary target for mediating the effect of $\alpha$-tomatine in leukemia cells. The present study also indicates that the glycone component is critical for $\alpha$-tomatine to convey signals for growth inhibition and apoptosis. The results from the present study indicate that $\alpha$-tomatine may be a candidate for the development of novel anti-leukemia agents.

\section{Acknowledgements}

The present study was supported by the Guangdong Province Leadership Grant, China National Science Foundation 
(grant nos. 81272452, 21102020 and 21272043) and the Rutgers Cancer Institute of New Jersey (grant no. CCSG P30-CA072720 RSD).

\section{References}

1. Willker W and Leibfritz D: Complete assignment and conformational studies of tomatine and tomatidine. Magn Reson Chem 30 645-650, 1992

2. Friedman M: Tomato glycoalkaloids: role in the plant and in the diet. J Agric Food Chem 50: 5751-5780, 2002.

3. Roddick JG: The steroidal glycoalkaloid $\alpha$-tomatine. Phytochemistry 13: 9-25, 1974.

4. Lairini K, Perez-Espinosa A, Pineda M and Ruiz-Rubio M: Purification and characterization of tomatinase from Fusarium oxysporum f. sp. lycopersici. Appl Environ Microbiol 62: 1604-1609, 1996.

5. Blankemeyer JT, White JB, Stringer BK and Friedman M: Effect of $\alpha$-tomatine and tomatidine on membrane potential of frog embryos and active transport of ions in frog skin. Food Chem Toxicol 35: 639-646, 1997.

6. Jiratko J: Comparison of antifungal activity of tomatine and tomato extract. Ochrani Rostlenia 29: 93-98, 1993.

7. Chan HT and Tam SYT: Toxicity of $\alpha$-tomatine to larvae of the Mediterranean fruit fly (Diptera: Tephrididae). J Economic Entomology 78: 305-307, 1985.

8. Chu YI and Lu FM: The ovicidal effect of tomatine against deposited eggs of the diamondback moth, Plutella xylostella $\mathrm{L}$. Chinese Journal of Entomology 12: 213-216, 1992.

9. Weissenberg M, Levy A, Svoboda JA and Ishaaya I: The effect of some Solanum steroidal alkaloids and glycoalkaloids on larvae of the red flour beetle, Tribolium castaneum, and the tobacco hornworm, Manduca sexta. Phytochemistry 47: 203-209, 1998.

10. Chataing B, Concepcion JL, Lobaton R and Usubillaga A: Inhibition of Trypanosoma cruzi growth in vitro by Solanum alkaloids: a comparison with ketoconazole. Planta Med 64 31-36, 1998.

11. Bergers Lee WW and Alink GM: Toxic effect of the glycoalkaloids solanine and tomatine on cultured neonatal rat heart cells. Toxicol Lett 6: 29-32, 1980.

12. Lee KR, Kozukue N, Han JS, et al: Glycoalkaloids and metabolites inhibit the growth of human colon (HT29) and liver (HepG2) cancer cells. J Agric Food Chem 52: 2832-2839, 2004.

13. Shieh JM, Cheng TH, Shi MD, et al: $\alpha$-Tomatine suppresses invasion and migration of human non-small cell lung cancer NCI-H460 cells through inactivating FAK/PI3K/Akt signaling pathway and reducing binding activity of NF- $\kappa \mathrm{B}$. Cell Biochem Biophys 60: 297-310, 2011.

14. Shih YW, Shieh JM, Wu PF, et al: $\alpha$-tomatine inactivates PI3K/Akt and ERK signaling pathways in human lung adenocarcinoma A549 cells: effect on metastasis. Food Chem Toxicol 47: 1985-1995, 2009.

15. Lee ST, Wong PF, Cheah SC and Mustafa MR: $\alpha$-tomatine induces apoptosis and inhibits nuclear factor- $\kappa \mathrm{B}$ activation on human prostatic adenocarcinoma PC-3 cells. PLoS One 6: e18915, 2011.

16. Chao MW, Chen $\mathrm{CH}$, Chang YL, et al: $\alpha$-Tomatine-mediated anti-cancer activity in vitro and in vivo through cell cycle- and caspase-independent pathways. PLoS One 7: e44039, 2012.

17. Yang YW, Wu CA and Morrow WJ: The apoptotic and necrotic effects of tomatine adjuvant. Vaccine 22: 2316-2327, 2004.

18. Collins SJ: The HL-60 promyelocytic leukemia cell line: proliferation, differentiation, and cellular oncogene expression. Blood 70: 1233-1244, 1987.
19. Semizarov D, Glesne D, Laouar A, et al: A lineage-specific protein kinase crucial for myeloid maturation. Proc Natl Acad Sci USA 95: 15412-15417, 1998.

20. Zheng X, Chang RL, Cui XX, et al: Synergistic effects of clinically achievable concentrations of 12-O-tetradecanoylphorbol-13-acetate in combination with all-trans retinoic acid, $1 \alpha, 25$ dihydroxyvitamin $\mathrm{D} 3$, and sodium butyrate on differentiation in HL-60 cells. Oncol Res 12: 419-427, 2000

21. Zheng X, Cui XX, Khor TO, et al: Inhibitory effect of a $\gamma$-tocopherol-rich mixture of tocopherols on the formation and growth of LNCaP prostate tumors in immunodeficient mice. Cancers (Basel) 3: 3762-3772, 2011.

22. Hansson A, Marín YE, Suh J, et al: Enhancement of TPA-induced growth inhibition and apoptosis in myeloid leukemia cells by BAY 11-7082, an NF- $\kappa B$ inhibitor. Int J Oncol 27: 941-948, 2005.

23. Micich TJ: Behavior of polymer-supported tomatine toward cholesterol in the presence and absence of butter oil. J Agricu Food Chem 39: 1610-1613, 1993

24. Roddick JG: Complex formation between solanaceous steroidal glycoalkaloids and free sterols in vitro. Phytochemistry 18: 1467-1470, 1979.

25. Maiti A, Cuendet M, Kondratyuk T, et al: Synthesis and cancer chemopreventive activity of zapotin, a natural product from Casimiroa edulis. J Med Chem 50: 350-355, 2007.

26. Kamiya T, Makino J, Hara H, et al: Extracellular-superoxide dismutase expression during monocytic differentiation of U937 cells. J Cell Biochem 112: 244-255, 2011.

27. Bortul R, Tazzari PL, Cappellini A, et al: Constitutively active Akt1 protects HL60 leukemia cells from TRAIL-induced apoptosis through a mechanism involving $\mathrm{NF}-\kappa \mathrm{B}$ activation and cFLIP(L) up-regulation. Leukemia 17: 379-389, 2003.

28. Baldwin AS: Control of oncogenesis and cancer therapy resistance by the transcription factor NF-кB. J Clin Invest 107: 241-246, 2001.

29. Cuní S, Pérez-Aciego P, Pérez-Chacón G, et al: A sustained activation of PI3K/NF- $\mathrm{KB}$ pathway is critical for the survival of chronic lymphocytic leukemia B cells. Leukemia 18: 1391-1400, 2004.

30. Friedman M and McDonald GM: Potato glycoalkaloids: chemistry, analysis, safety, and plant physiology. Crit Rev Plant Sci 16: 55-132, 1997.

31. Friedman M: Anticarcinogenic, cardioprotective, and other health benefits of tomato compounds lycopene, $\alpha$-tomatine, and tomatidine in pure form and in fresh and processed tomatoes. J Agric Food Chem 61: 9534-9550, 2013.

32. Severs NJ and Simms HL: Failure of filipin to detect cholesterol-rich domains in smooth muscle plasma membane. Nature 303: 637-638, 1983.

33. Keukens EAJ, de Vrije T, van den Boom C, et al: Molecular basis of glycoalkaloid induced membrane disruption. Biochim Biophys Acta 1240: 216-228, 1995.

34. Roddick JG, Rijnenberg AL and Osman SF: Synergistic interaction between potato glycoalkaloids $\alpha$-solanine and $\alpha$-chaconine in relation to destabilization of cell membranes: Ecological implications. J Chem Ecol 14: 889-902, 1988.

35. Cayen MN: Effect of dietary tomatine on cholesterol metabolism in the rat. J Lipid Res 12: 482-490, 1971.

36. Friedman M, Henika PR and Mackey BE: Feeding of potato, tomato and eggplant alkaloids affects food consumption and body and liver weights in mice. J Nutr 126: 989-999, 1996.

37. Wilson RH, Poley GW and De Eds F: Some pharmacologic and toxicologic properties of tomatine and its derivatives. Toxicol Appl Pharmacol 3: 39-48, 1961.

38. Nishie K, Norred WP and Swain AP: Pharmacology and toxicology of chaconine and tomatine. Res Comm Chem Pathol Pharm 12: 657-668, 1975. 